LICENÇA CC BY:

Artigo distribuído sob os termos

Creative Commons, permite uso e distribuição irrestrita em qualquer meio desde que $o$ autor credite a fonte original.

\title{
A BANALIZAÇÃO DA INJUSTIÇA SOCIAL E A PEDAGOGIA DO SOFRIMENTO: CATEGORIAS PARA PENSAR A EDUCAÇÃO SOB O NEOLIBERALISMO
}

THE BANALIZATION OF SOCIAL INJUSTICE AND THE PEDAGOGY OF SUFFERING: CATEGORIES FOR THINKING ABOUT EDUCATION UNDER NEOLIBERALISM

LA BANALIZACIÓN DE LA INJUSTICIA SOCIAL Y LA PEDAGOGÍA DEL SUFRIMIENTO: CATEGORÍAS PARA PENSAR LA EDUCACIÓN BAJO EL NEOLIBERALISMO

Allan da Silva Coelho ${ }^{1}$ José Ailton Carlos Lima Correia²

${ }^{1}$ Doutor em Ciências da Religião pela UMESP. Docente do Programa de Pósgraduação em Educação da Universidade Metodista de Piracicaba (UNIMEP),

Piracicaba, SP, Brasil.

${ }^{2}$ Mestre em Educação pela Universidade Metodista de Piracicaba (UNIMEP), Piracicaba, SP, Brasil.

Resumo: O presente artigo objetiva analisar o sofrimento humano causado nas relações de trabalho pelas novas exigências do mercado neoliberal; da sua violência psicológica e da instauração da banalização de injustiça social. Nossa pesquisa bibliográfica, na perspectiva da crítica filosófica, se inscreve nos possíveis espaços dos mecanismos subjetivos de dominação do neoliberalismo; os efeitos psíquicos sobre o humano que se tornam devastadores, cujos sofrimentos sociais se somatizam na sociedade e nem sempre são considerados estruturalmente pela educação. Consideramos o neoliberalismo como a manifestação da nova racionalidade global, como Pierre Dardot e Christian Laval (2016), a qual impera nos governos locais; mas, sobretudo, assume a própria conduta dos governados, impondo tacitamente a criação de uma nova ética pela qual as relações sociais se estabelecem: o mercado e os homens empresa. Trata-se de um mecanismo subjetivo de colonização contemporânea, cuja nova moralidade mercantil subalterniza e dociliza consciências. Pela subalternização, identificamos a intimidação e o medo nas relações trabalhistas como novas táticas de dominações, como apontam Paulo Arantes (2014) e Cristophe Dejours (2001). O sofrimento social é consequência desse novo ethos-racional capitalista. Também, no escopo dessa investigação, apontamos como lastro desse sofrimento social a categorização estrutural da pedagogia do sofrimento e do sacrifício necessário na sociedade, analisados por Veena Das (2008), como construtos de coesão social, conformação e legitimação dessa nova moralidade neoliberal por meio da própria cultura e da educação para consolidação da sociedade moderna.

Palavras chaves: Razão neoliberal; Sofrimento social; Colaboração. 
Abstract: This article analyzes the human suffering caused in labor relations by the new demands of the neoliberal market, with its psychological violence and the institutionalization of the banalization of social injustice. Our bibliographical research, from a perspective of philosophical criticism, is inscribed in the possible spaces of the subjective mechanisms of domination of neoliberalism; the psychic effects on the human that become devastating, whose social sufferings are somatized in society and are not always structurally considered by education. We consider neoliberalism as the manifestation of the new global rationality, expounded by authors such as Pierre Dardot and Christian Laval (2016), which prevails in local governments; but above all, it assumes the very conduct of the governed by tacitly imposing the creation of a new ethic by which social relations are established: the market and businessmen. It is a subjective mechanism of contemporary colonization whose new mercantile morality subalternizes consciences and makes them docile. By subalternization, we identify intimidation and fear in labor relations as new tactics of domination, as pointed out by Paulo Arantes (2014) and Cristophe Dejours (2001). Social suffering is the consequence of this new capitalist ethos-rationale. Also, in the scope of this investigation, we point to the structural categorization of the pedagogy of suffering and the necessary sacrifice in society, analyzed by Veena Das (2008), as constructs of social cohesion, conformation and legitimation of this new neoliberal morality through culture and education for the consolidation of modern society.

Keywords: Neoliberal reason; Social suffering; Collaboration.

Resumen: El presente artículo tiene por objeto analizar el sufrimiento humano causado en las relaciones de trabajo por las nuevas exigencias del mercado neoliberal; de su violencia psicológica y la instauración de la banalización de la injusticia social. Nuestra investigación bibliográfica, en la perspectiva de la crítica filosófica, se inscribe en los posibles espacios de los mecanismos subjetivos de dominación del neoliberalismo; los efectos psíquicos sobre lo humano que se vuelven devastadores cuyos sufrimientos sociales se somatizan en la sociedad y no siempre son considerados estructuralmente por la educación. Consideramos el neoliberalismo como la manifestación de la nueva racionalidad global, como Pierre Dardot y Christian Laval (2016), que impera en los gobiernos locales; pero, sobre todo, asume la propia conducta de los gobernados imponiendo tácitamente la creación de una nueva ética por la cual las relaciones sociales se establecen: el mercado y los hombres empresa. Se trata de un mecanismo subjetivo de colonización contemporánea cuya nueva moralidad mercantil subalterniza y dociliza conciencias. Por la subalternización, identificamos la intimidación y el miedo en las relaciones laborales como nuevas tácticas de dominaciones como apuntan Paulo Arantes (2014) y Cristophe Dejours (2001). El sufrimiento social es consecuencia de ese nuevo ethos racionalista capitalista. En el ámbito de esta investigación, apuntamos como lastre de ese sufrimiento social, la categorización estructural de la pedagogía del sufrimiento y del sacrificio necesario en la sociedad, analizados por Veena Das (2008), como constructos de cohesión social, conformación y legitimación de esa nueva moralidad neoliberal a través de la propia cultura y educación para la consolidación de la sociedad moderna.

Palabras clave: Razón neoliberal; Sufrimiento social; Colaboración.

\section{Introdução}

As mudanças que o neoliberalismo implementa na sociedade capitalista atingiram não apenas a esfera da vida econômica, mas provavelmente a totalidade da vida social. Novas configurações de relações foram consolidadas e comportamentos sociais se 
alteraram em uma reorganização estrutural do sistema, como exigência de uma nova ordem de racionalização em que o mercado é o critério absoluto. Essa reorganização social, para o mercado de trabalho e consumo, apresenta contradições específicas, como em outros momentos históricos do capitalismo, as quais geram situações sociais importantes pelas empresas que nem sempre são explicitadas pelos estudos.

Nossa proposta é, a partir da leitura de autores críticos do capitalismo neoliberal, como Paulo Arantes, Christopher Dejours, Pierre Dardot e Christian Laval, destacando em especial a noção de sofrimento social provocado pela engenharia do trabalho sob a égide da precarização das relações trabalhistas atuais, promover uma reflexão dialógica com as teorias de justificação teológica do sofrimento, tendo como referência de destaque a antropóloga Veena Das. A intenção é articular categorias de análise crítica da realidade, as quais permitam ampliar o horizonte do debate sobre o já vasto e interessante debate sobre o neoliberalismo na educação.

Partimos do pressuposto que a principal premissa ética está na diferenciação do mal e do bem, sendo que o comportamento adequado é o bem, atribuindo a noção de mal àquela postura humana que se pretende rechaçada. No entanto, o mal historicamente é praticado como se fosse bem, a partir de certas inversões éticas, por vezes, legitimadas sob imaginário teológico-religioso. Sob o neoliberalismo, o mal que praticamos como se fosse o bem se apresenta como:

\footnotetext{
Um sistema de gestão, como um princípio organizacional: das empresas, dos governos, de todas as instituições e atividades, em suma, que, organizadas segundo este mesmo princípio, foram se convertendo em centros difusores de uma nova violência e incubadoras de seus agentes, os ditos colaboradores de nosso tempo (ARANTES, 2014, p. 102, grifos nossos).
}

Ao refletirmos sobre tal princípio organizacional e suas consequências na "difusão" de um novo tipo de violência", bem como no processo de formação dos "colaboradores de nosso tempo", apontamos a necessidade da filosofia da educação trazer ao centro das discussões as novas relações sociais decorrentes das novas exigências do mercado e do trabalho, com suas profundas exigências para as escolas e os projetos de formação humana. Hoje, uma crise estrutural se estabelece como um fator preponderante para a saída da própria crise do mercado, que não angaria mais os lucros espetaculares como na aurora capitalista. É a crise fabricada como causa e não simples consequência. $A$ crise não é mais um fato isolado de mundos locais; tornou-se um estado de exceção (Agamben) normatizado à categoria social estruturalizante para garantir a sobrevivência do próprio mercado. Destarte, a visibilidade da violência, que outrora assolava a sociedade do capitalismo industrial, hoje, transmutou-se em despercebimento social travestido de benefícios de mercado, consumo e adesão social pelo trabalho, o que a torna de difícil identificação pela sociedade. É o mal, entendido como o bem, com adesão colaborativa, apesar da experiência real e concreta do sofrimento social.

Paulo Arantes propõe sua questão central com a seguinte formulação: "Como explicar que 'pessoas de bem' se deixam arregimentar para o exercício do mal como 
princípio organizacional, como princípio sistêmico de gestão de empresas e governos regidos pela mesma racionalidade que anima os novos controles capitalistas?" (ARANTES, 2014, p. 110-111). O objetivo desse artigo é iniciar uma reflexão sobre os possíveis mecanismos subjetivos que engendram essa velada dominação neoliberal e sua implicação para a própria educação.

Hodiernamente, no âmbito do trabalho, o neoliberalismo organiza a produção globalizada utilizando todos os meios tecnológicos e comunicacionais, grande marca de sua nova configuração capitalista, buscando sempre maximizar os lucros, baratear a produção com novas estratégias e a contratação de trabalhadores com salários cada vez mais baixos e sem garantias sociais. Associado à política do Estado mínimo social e Estado máximo de controle e repressão, pelo qual se estabelece a total liberdade para a efetivação do mercado, de circulação de dinheiro e mercadorias, o neoliberalismo tornou-se o sistema que eleva o índice do desemprego e a desigualdade social no globo. Seu critério de atuação está no resultado da acumulação sem precedentes de lucro, não em desenvolvimento humano e social.

As chamadas reformas neoliberais estão precarizando as relações de trabalho pelo mundo todo, substituindo direitos conquistados pelas lutas sociais por condições trabalhistas vulneráveis. Nessa perspectiva, o trabalhador empreende todas as ações (im)possíveis para manutenção de sua empregabilidade, ainda que sejam antiéticas e contra sua própria moralidade; essas se justificariam à legalidade neoliberal, que tudo permite para a organicidade e para o alto desempenho do lucro das empresas. Dessa forma, o trabalhador se vê sempre desafiado, por ele mesmo, a pensar e criar o tempo todo sobre o trabalho, buscando sempre novas formas de superação que realcem suas categorias de bom indivíduo funcional.

Pierre Dardot e Christian Laval (2016) denunciam o perfil do novo comportamento social proveniente dessa modalidade racional:

\footnotetext{
A tese defendida por esta obra é precisamente que o neoliberalismo, antes de ser uma ideologia ou uma política econômica, é em primeiro lugar e fundamentalmente uma racionalidade e, como tal, tende a estruturar e organizar não apenas a ação dos governantes, mas até a própria conduta dos governados. [...] O termo racionalidade não é empregado aqui como um eufemismo que nos permite evitar a palavra "capitalismo". O neoliberalismo é a razão do capitalismo contemporâneo, de um capitalismo desimpedido de suas referências arcaizantes e plenamente assumido como construção histórica e norma geral da vida (DARDOT \& LAVAL, 2016, p. 17).
}

Assim, a nossa abordagem indica que o neoliberalismo necessita de um tipo de racionalidade que busca sua fundamentação em um tipo de teodiceia, como justificação teológica-religiosa secularizada, mas presente e atuante, a qual relaciona trabalho ao sofrimento irrecusável e necessário para construção e consolidação do ethos social. Dessa maneira, a relação trabalho e sociedade estaria intimamente relacionada à pedagogia do sofrimento pela qual os seres sociais são educados para a conformação e adesão ao sistema: trabalho, mercado e consumo. 


\section{medo como princípio organizacional e de sobrevivência}

As grandes modificações que ocorreram nas relações de mercado e o impacto das inovações tecnológicas no mundo geraram novas formas de gestão de empresas no trabalho contemporâneo, tais como: qualidade total; excelência nos métodos; metas e objetivos; cobranças normatizadas; e outras técnicas relacionadas à produtividade máxima para o êxito no mercado. Então, para a máxima eficiência de uma empresa, as angústias e as pressões no trabalho são tidas como condições normais para o bom funcionamento da máquina administrativa. O sofrimento dos trabalhadores tornouse o motor da história do desenvolvimento das empresas. Cristophe Dejours associa a empresa moderna a um "organismo vivo" que luta pela saúde de seu corpo e deve fazer tudo que é possível para sobreviver:

\footnotetext{
A guerra sã é antes de tudo uma guerra pela saúde (das empresas); "enxugar os quadros", "tirar o excesso de gordura" (Alain Juppé), "arrumar a casa", "passar o aspirador", "fazer uma faxina", "desoxidar", tirar o tártaro", "combater a esclerose ou a ancilose" etc., eis algumas expressões colhidas aqui e ali na linguagem corrente dos dirigentes (DEJOURS, 2007, p. 14).
}

Essas expressões correntes, decorrentes da nova gestão empresarial, em curso no neoliberalismo, introduzem como fator absolutamente tensionante: o medo da perda do emprego por parte do trabalhador e a intimidação silenciosa por parte do patronato; o que, sem dúvidas, torna o trabalhador mais tenso, vulnerável e submisso ao sistema vigente. Para Dejours, essa nova maquinaria de guerra silenciosa, a qual gera sofrimentos sociais, só funciona pelo consentimento dos trabalhadores: "Que a máquina de guerra funcione, por sua vez, pressupõe que todos os outros (os que não são "decisores"), ou pelo menos a maioria deles, contribuem para o seu funcionamento, sua eficácia e sua longevidade, ou, em todo caso, que não a impedem de continuar em movimento" (DEJOURS, 2007, p. 16).

Trata-se, portanto, de um trabalho que precisa ser executado pelo medo da exclusão ou da demissão, pelo qual superamos todos os escrúpulos individuais e a ética da relação com o outro para realização de tarefas. É o que Paulo Arantes chamou de Sale boulot (trabalho sujo); já que estamos tratando da pesquisa de um psiquiatra francês que trata este fenômeno na clínica do trabalho. Arantes destaca que o silencioso medo, imposto pelas empresas, é utilizado como uma alavanca útil para fazer trabalhar e operar dinamicamente as empresas. Neste ambiente de trabalho intimidado, os trabalhadores, de um modo geral, estão atentos a tudo. Assim, o medo compartilhado cria uma dinâmica para a eficiência máxima:

Para surpresa das certezas clássicas acerca da motivação no trabalho, assentadas na convicção de que só a livre vontade dos trabalhadores mobiliza inteligência e engenho, o novo management revelou que o zelo passou a responder à pressão do medo, que em vez de paralisar a inteligência pode desovar tesouros de inventividade para melhorar a produção e constranger os vizinhos (ARANTES, 2014, p. 129). 
$\mathrm{Na}$ perspectiva dessa funcionalidade pelo consentimento e adesão, o neoliberalismo impõe a sua fúria econômica em todo globo, não apenas nos países periféricos. São os pobres as maiores vítimas. O homem de bem se sente sempre devedor do Sistema; pois, afinal, nele foi inferida a falsa consciência de que é um escolhido dentre um sem fim de desempregados. Assim, o trabalhador precisa doar o ser, superar as dores provocadas pelas exigências laborais quase desumanas, vivendo na perspectiva de uma fidelidade canina, sempre disponível, de prontidão e pronto a abrir mão de direitos ou assumir novos trabalhos e metas. Também não é raro se sentir culpado por nunca ser o suficientemente competente diante das estrondosas transformações no mercado, o que faz do trabalhador um humano sempre aquém das exigências do seu trabalho. Desta feita, ele precisa trabalhar sempre mais; pois carrega dívida e culpa, o que fazem dele um servo dócil, quase um escravo-voluntário.

$\mathrm{Na}$ escravidão por dívida e culpa, encontramos um componente psicoideológico importante para o desenvolvimento da subalternização da consciência humana: ao contrário do escravo capturado ou prisioneiro de guerra, o escravo por dívida e culpa não tem revolta em relação ao seu dono; ao contrário, vê no seu esforço e dedicação formas de produzir sempre mais, de modo a reconquistar a liberdade perdida e ser reconhecido socialmente.

Dessa maneira, como realça Dejours, homens e mulheres criam defesas particulares para a sobrevivência no trabalho cheias de sutilezas e criatividades. "Destarte, para se submeterem às novas estratégias das relações de trabalho, homens e mulheres criam defesas contra o sofrimento padecido no trabalho. As 'estratégias de defesa' são sutis, cheias mesmo de engenhosidade, diversidade e inventividade" (DEJOURS, 2007, p. 18).

\section{O homem empresa: zona cinzenta, colaboração e trabalho como zelo}

Paulo Arantes ilustra o conceito a partir de Primo Levi no seu livro Os afogados e os sobreviventes (1990), partindo de certa confraternização mediada por um jogo de futebol histórico entre os prisioneiros e os carcereiros no campo de concentração nazista. O improvável acaba ocorrendo nesta obscura zona cinzenta:

\footnotetext{
Essa partida poderá parecer a alguém como se fosse uma breve pausa de humanidade em meio a um horror infinito. Aos meus olhos, porém, como aos das testemunhas, tal partida, tal momento de normalidade, é o verdadeiro horror do campo. [...] aquela partida nunca terminou, é como se continuasse ainda, ininterruptamente. Ela é o emblema perfeito e externo da "zona cinzenta" que não conhece tempo e está em todos os lugares. [...] dela também provém a nossa vergonha, de nós que não conhecemos os campos e que, mesmo assim, assistimos, não se sabe como, àquela partida que se repete em cada partida dos nossos estádios, em cada transmissão televisiva. Em cada normalidade cotidiana. Se não conseguirmos entender aquela partida, acabar com ela, nunca mais haverá esperança (ARANTES, 2014, p. 112-113).
}

Na perspectiva contemporânea, o conceito de Zona cinzenta atualiza-se para o lugar do trabalho e do mercado, de uma impensável comunhão entre colaboradores no 
neoliberalismo: as vítimas que são impelidas a praticarem o trabalho sujo pelo medo da demissão e intimidações subjetivas, e os perpetradores do mal, os dominadores. Um encontro relacional inusitado que moralmente seria reprovável: é a banalização da injustiça social. Aqui, pelo viés do trabalhador-dominado, percebemos a dissimulação fabricada para sustentação da sua necessária sobrevivência. Na direção do dominador, identificamos o engendramento de sua falsa generosidade (Paulo Freire), a fim de controlar-orientar suas vítimas para melhor produtividade.

Dessa maneira, acostumando e se conformando ao sistema aviltante, o trabalhador, em nome da sobrevivência e da segurança, chega ao lugar da inquietante zona cinzenta, ou, para melhores esclarecimentos: o sistema de colaboração moderno.

Outra perspectiva importante na concepção do sofrimento social é o zelo no trabalho, que se torna o elemento determinante para o êxito do neoliberalismo. Não bastam apenas as pessoas se anularem pelo trabalho sujo dentro da Zona cinzenta do mercado; urge que elas sejam criativas, inventivas e que façam além das exigências de suas funções. Segundo Christian Dejours, não basta ser um cumpridor de tarefas; é preciso amar zelosamente o trabalho, que não é totalmente inteligível, formalizável e automatizável. Arantes analisa:

Não se trata obviamente do trivial esmero de quem quer agradar o comprador de seu saber-fazer, mas de outra coisa - quem de fato trabalha sempre "faz outra coisa", por mais que pareça seguir escrupulosamente um script -, que ao cessar pode acarretar a pane de todo um sistema técnico produtivo. Não se trata de uma qualidade contingente do trabalhador, o zelo é não só central, mas decisivo, insiste Dejours (ARANTES, 2014, p. 126).

Assim, a colaboração e o zelo no trabalho, termos apropriados para a subsistência na vida moderna, passam a forjar pedagogicamente a consciência do novo sujeito-social sob a égide da cultura neoliberal: a identidade subjetiva empresarial, como afirmam Dardot e Laval: "Todo indivíduo tem algo de empreendedorismo dentro dele, e é característica da economia de mercado liberar e estimular esse "empreendedorismo" humano (DARDOT \& LAVAL, 2016, p. 145). Portanto, trata-se de uma ideologia econômica que plasma no sujeito social uma autoeducação, sua própria formação:

[...] o empreendedorismo não é apenas um comportamento "economizante", isto é, que visa à maximização dos lucros. Ele também comporta a dimensão "extraeconomizante" da atividade de descobrir, detectar "boas oportunidades". A liberdade de ação é a possibilidade de testar suas faculdades, aprender, corrigir-se, adaptar-se. O mercado é um processo de formação de si (DARDOT \& LAVAL, 2016, p. 145).

Nessa perspectiva neoliberal, a empresa deixa de ser uma simples instituição coletiva para assumir uma condição individual, como uma mônada econômica que se relaciona com outras empresas humanas pela lógica racional do mercado. Esse mecanismo é também gerador de sofrimentos sociais; pois, "transferindo os riscos para os assalariados, produzindo o aumento de sensação de risco, as empresas puderam exigir deles disponibilidade e comprometimento muito maiores" (DARDOT \& LAVAL, 2016, p. 329). 


\section{Mercado de trabalho e mercado de consumo: Medo e adesão na realização humana}

Tal colaboração ativa pode ser compreendida na articulação entre medo e promessa, simultaneamente. $O$ medo do fracasso no mercado de trabalho tem sua interface direta com o medo do fracasso no mercado consumidor. Ao mesmo tempo em que o trabalhador adere colaborativamente às condições precárias de trabalho, manifesta sua adesão ao modelo de vida neoliberal ao apostar sua realização como pessoa humana nas relações de consumo de mercadoria (COELHO, 2014). As mercadorias, como resultado articulado do trabalho e porta de passagem para o lucro, prometem a redenção do colaborador que, dedicado e sofredor, pode expiar seu sofrimento nos encantos do consumo.

A adesão é reorientada para a uma nova dimensão de coesão social sobre a vida moderna: a aposta no mercado. Para isto é preciso encantar a vida com o poder do consumo, tema bastante discutido por um setor do pensamento crítico latino-americano, como por Jung Mo Sung, que diz:

Encantar a vida através do mundo do consumo e a fé no mito do mercado livre formam pilares essenciais de uma civilização que colocou o mercado no lugar antes ocupado pelo sagrado das religiões tradicionais. As religiões tradicionais saíram ou perderam a força da esfera pública das nossas sociedades, que antes eram tratadas por essas religiões, não perderam a sua vigência. Agora são tratadas e dirigidas pelo mercado. O capitalismo se tornou uma religião da vida cotidiana (Marx), com suas devoções, espiritualidade, mitos e ritos, só que com a vantagem de não receber as críticas feitas às religiões (SUNG, 2006, p. 79).

Assim, mercado (de trabalho ou de consumo, o mesmo mercado afinal) passa a ser a medida de todas as coisas na vida do homem moderno, do homem-empresa. O trabalho na modernidade não é mais entendido como um meio de subsistência e provisão; mas, sim, o objetivo supremo que logra condições de afirmação, pertencimento social e formação da identidade humana.

As pessoas trabalham cada vez mais para acumular e consumir cada vez mais, não porque seja necessário ou útil, mas porque "somos o que consumimos", ou melhor, somos tratados de acordo com o nosso padrão de consumo, e também porque o consumir encanta a nossa vida. [...] Se países, empresas e pessoas lutam umas contra as outras no mercado e na cultura de consumo para "serem" mais através de ter e ostentar mais riquezas, o outro lado da história é feito de países, empresas e pessoas que são derrotadas e deixados para trás na corrida para "ser" mais (SUNG, 2006, p. 72-73).

Assim, as pessoas consentem e colaboram com o sistema, numa submissão às novas exigências das leis do mercado, em função do elenco de promessas de recompensas como se disponíveis a elas; essas se tornam mercadorias-símbolos que afirmam a identidade humana e autoestima pessoal criando sentido de pertencimento social:

O sentido fundamental da vida na nossa civilização é o de viver em função de acumular mais e mais riquezas, pois, essa acumulação ostentada através de mercadorias-signos, especialmente de griffes, nos garante o reconhecimento social, a auto-estima e a identidade que nos permite situar em posições de destaque e fazer parte de grupos bem posicionados na sociedade. A complementariedade ao nível macrossocial desse sentido de vida é a ideologia neoliberal que prega que não há salvação fora do mercado, que só o mercado livre pode nos garantir mais eficiência para maior acumulação de riqueza (SUNG, 2006, p. 78). 
Essa adesão-dominação silenciosa em curso na sociedade formula um jeito de ser humano, com disfuncionalidades concretas na vida, e tem esvaziado ao sentido humano de ser simplesmente humano, fazendo prevalecer apenas os interesses cambiais de mercado, trabalho e consumo. A adesão colaborativa articula e expressa o medo de não se realizar e o desejo de conquistar a realização pelo consumo, horizonte do real possível. Expressa e articula o sofrer e a justificativa do sofrimento como sacrifício necessário, mal que produz o bem. Esta breve passagem pela questão da sedução pelo consumo permite que continuemos nosso propósito.

\section{Banalização da injustiça social: Dejours e Arendt}

Paulo Arantes e Christopher Dejours indicam que na reengenharia do sistema capitalista, o neoliberalismo, o medo tornou-se o elemento propulsor, central, organizador e integrador para a construção do tecido social. Assinalamos que o medo tem sua dimensão na relação de produção, mas também na relação de distribuição e consumo de mercadorias. Dejours dialoga com o conceito de banalização do mal de Hannah Arendt ao defender que o denominador comum entre as pessoas que sofrem no mercado é o trabalho pelo medo. Seria a partir da psicodinâmica das relações trabalhistas que podemos atualizar a categoria de Arendt. A dissertação de mestrado de Lima (2018) acompanha a leitura de Paulo Arantes, destacando que os mecanismos subjetivos da dominação supõem um farto dispositivo de banalização do mal. Conforme Dejours percebeu, escapou a Arendt que não apenas o vazio do pensamento pode tornar o humano colaborativo com o sofrimento, mas a engenharia do trabalho tem potencial para o mesmo.

Assim, pelas análises dejourianas, a faculdade do pensar pode estar prejudicada suspensa - em momentos específicos de adversidade, como no caso da banalização da injustiça social no trabalho, a qual pode estar submetida; no entanto, outros setores da vida podem efetivamente ser pensados sem prejuízos pela faculdade do pensar:

Retomando os termos arendtianos, a "faculdade do pensar" só é suspensa num setor preciso da relação com o mundo e com o outro: o setor psíquico diretamente relacionado com a adversidade alheia. Em compensação, a faculdade do pensar continua se exercendo apropriadamente em todos os demais aspectos da vida (por exemplo, na vida privada, na educação dos filhos, nas atividades artísticas e culturais). Trata-se, por assim, dizer, de uma falta de capacidade de pensar "setorial" ou uma estupidez setorial (DEJOURS, 2007, p. 118-119).

Ou seja, as pessoas sofrem concretamente, e a banalização do mal não é apenas o esvaziamento do pensamento; mas, sobretudo, estaria mais relacionada às categorias do sofrimento no trabalho as quais geram deformidades sociais e prejuízos à subjetividade humana, e não como comumente relacionamos à condição de alienação:

[...] o problema da alienação se reformula por inteiro, adotando inclusive a altamente enfática e ambígua semântica do mal - adormecida desde o escândalo político e moral provocado pelo caso Eichmann segundo Hannah Arendt, e ressuscitada como névoa de guerra social a partir dos anos de 1970, de tal sorte que é próprio trabalho gerador de infelicidade, alienação e doença mental que fornece a chave explicativa das estratégias de defesa entranhadas nos comportamentos de 
aceitação do mal, para se adaptar ao sofrimento acarretado pelo medo, medo esse, sabidamente, o principal combustível das tecnologias neoliberais de poder (ARANTES, 2014, p. 110).

Logo, precisamos considerar as categorias de sofrimento envolvidas nas realidades concretas da vida; das relações sociais no mercado de trabalho. Que tipo de processos educativos permitem não apenas o esvaziamento do pensar crítico, mas, ainda, legitima o sofrimento como colaboração, assumindo a função de certa teodiceia?

\section{Educação: a pedagogia do sofrimento e a banalização da injustiça social}

Há diversas maneiras de pensar como a educação foi invadida pela razão neoliberal. São inúmeras as perspectivas positivistas da cientificidade e orientações para o mercado as quais passaram a predominar na educação e seu processo educacional: qualidade total, modernização da escola, adequação do ensino à competitividade do mercado empresarial, planilhas de análises e avaliações objetivas, incorporação de técnicas e linguagens de mercado, informatização plena, comunicação de massas, nexo de universidades e mercados, pesquisas utilitárias e de produtividade, sistema em rede em universidades, etc.

Dessa forma, o neoliberalismo vê a educação como a maneira específica de dinamizar e consolidar a sua ideologia, normatizando-a e preparando os novos sujeitos sociais para o mercado de trabalho e consumo. Há inúmeros autores importantes que tratam desta temática, entretanto delimitamos a nossa atenção aos aspectos subjetivos da dominação na aceitação do sofrimento pelas relações de trabalho e consumo, que engendram a banalização não simplesmente do mal, mas do sofrimento como injustiça social.

Para essa análise, os estudos da antropóloga indiana Veena Das tornamse pertinentes e importantes na medida em que adotamos como objeto de nossa pesquisa o tema sobre o sofrimento social. Temos interesse pela articulação entre os conceitos de sofrimento, teodiceia e pedagogia como proposto pela antropóloga como instrumentos analíticos. Veena Das não configurou uma teoria educacional, mas indica a relação entre as teodiceias que explicam e justificam o sofrimento humano na vida e as práticas pedagógicas existentes no sentido da consolidação de comportamentos válidos eticamente e considerados normais à vida em sociedade.

Desenvolvendo uma teodiceia em pleno mundo moderno, legitima-se o sofrimento como fundamento da racionalidade que procura exprimir coerência entre o sem razão do sofrimento e a ideia de sacrifício necessário. A plausibilidade desta compreensão de "ideal maior" (seja o divino, o progresso, a justiça, o bem maior, o futuro, etc.) assume plenamente seu potencial utópico.

Assim, para Das, a Teodiceia do sofrimento assume um poderoso princípio de sociabilidade, tornando-se a necessária pedagogia para disciplinar os corpos sociais 
para as relações de trabalho pela perspectiva dessa subjetividade do sofrimento, a fim de garantir um futuro promissor na sociedade. Isto passa a caracterizar um mecanismo de adesão ao ethos capitalista moderno. Os conceitos estão secularizados, mas a lógica do sacrifício necessário que justifica o sofrimento permanece teológica-religiosa, agora a serviço do capitalismo. Para Veena Das, é o marco de plausibilidade que advém das teodiceias que sustentam toda a "lógica" da racionalidade atual e supõe uma tal pedagogia na manutenção da legitimidade e na adesão à ordem social moderna. "Seu pilar central é educar o corpo, administrando um sentido geral para a vida humana (corpo submisso no trabalho e conformação de aspectos da subjetividade), o que configura a adesão ao ethos capitalista moderno" (COELHO, 2017, p. 50).

Nessa perspectiva disciplinadora, o tema que se torna central em suas pesquisas está na relação entre as instituições sociais, estruturadas pelas teodiceias, e o sofrimento real dos seres humanos vitimados pela violência social. Dessa maneira, a crítica de Das à configuração deste ethos que gera subalternização, como prática de poder e de exploração, que também se expressa nas relações de produção do saber, revela a insuficiência da compreensão do sofrimento humano nas relações sociais. Como mensurar a dor pelos mecanismos científicos? A análise de Das é importante do ponto de vista que a instância do sofrimento modifica significativamente as formas de compreender o mundo e as relações sociais, portanto transforma o próprio conhecimento. Para Das, o conhecimento deve ser perspectivado, ou seja, um saber que deve compreender o outro e reconhecer a sua dor. Então, conhecer é reconhecer.

A autora afirma que o conhecimento deve ser ampliado considerando os horizontes do sofrimento humano, pois o mesmo ressignifica a realidade da vida advinda de experiências concretas da existência e das condições sociais. "Para a antropóloga, o fato de que não há categorias analíticas nas ciências sociais modernas para expressar e entender o sofrer da vítima revela que se produz uma teoria crítica alheia à dor do outro" (COELHO, 2017, p.44). É importante ressaltar que a dor não reside apenas da criticidade; ela faz parte da cotidianidade da vida e deve ser considerada.

Nesse sentido, identificamos certa aproximação entre os conceitos de banalização de injustiça social, elemento da teoria de Dejours, o qual estabelece o sofrimento social como consequência defensiva dos trabalhadores - sale boulot e zelo - para a necessária adaptabilidade às relações de trabalho, sistema vigente e sociedade e, o sofrimento como pedagogia em Veena Das, agora como princípio estruturador da sociedade pelo qual se legitima a violência do corpo e pela cultura do sacrifício necessário para viver em uma sociedade e/ou se manter nas relações de trabalho. Este tema é relevante nos marcos dos estudos do funcionamento do capitalismo como religião. Seria necessária certa pedagogia, capaz de conformar os pressupostos e o conjunto de valores, sentidos e direções que orientam a compreensão da existência. Para isto, apoia-se em uma tradição mítica-teológica, sem a necessidade de associar-se às chamadas "religiões". Desloca-se 
para as instituições do Estado, do mercado e para outras com capacidade suficiente de propor modelos de humanidade e educar disciplinarmente para o referido modo de viver.

O esforço é tentar convencer que, seja no trabalho-produção ou no consumo, o sofrimento e a frustração não são puras arbitrariedades da vida, mas podem ser desvendadas como experiências gestadas e distribuídas de forma prevista pela própria ordem social. O sofrimento tem potencial de

\begin{abstract}
(...) "moldar" os seres humanos como membros morais da sociedade, revelada na dor que se "inflige" aos indivíduos em nome dos grandes projetos de sociedade (sacrifício necessário). Ambos estão articulados; o primeiro, na ação educativa para um sentido de viver; e o outro, como realidade simbólica que justifica e legitima esse modo de organizar a vida (COELHO, 2017, p. 46).
\end{abstract}

Desse modo, guardando os devidos limites entre os estudos dos autores, percebemos interessantes aproximações e complementariedades de Dejours e Das: A educação do corpo, descrito por Das, com a finalidade de forjar a resiliência necessária para suportar os sofrimentos e as adversidades, indispensáveis para o funcionamento do capitalismo, compenetrando as pessoas sempre no "resultado final", não estaria interligada à conformação social e ao consequente desenvolvimento de mecanismos subjetivos de defesa criados pelo trabalhador, diante da banalização da injustiça social no neoliberalismo, descrito por Dejours?

Não seria exagero pensar a educação pelo sofrimento e forjar a consciência de normalidade do sofrimento na injustiça social nas relações humanas que envolvem a vida no capitalismo. Dessa maneira, é preciso colonizar, subalternizar, docilizar e preparar os corpos sociais - os selvagens ao sistema - para que, a consciência humana, adaptada, seja coisificada para se alinhar aos ambientes desumanos que se restringem às relações de mercado. Às vítimas deste descalabro relacional mercantil, diante da inexorabilidade do sistema, restam-Ihes produzir sistemas subjetivos de defesa e segurança individuais frente ao sofrimento perpetrado pelo sistema.

Identificamos, assim, possivelmente, alguns eixos basilares para o sofrimento social: o sofrimento administrado pelas instituições sociais modernas que educa os corpos para a sociabilidade ao sistema dominante e os mecanismos subjetivos de defesa que são desenvolvidos para sobrevivência do indivíduo; além da nova racionalidade mercantilista que faz do ser social uma empresa instrumental que esteriliza as relações humanas e exacerba o individualismo competitivo e hostil. A justificação do sofrimento ao corpo pela teodiceia e a docilizado o corpo são o desenvolvimento das condições subjetivas do sofrimento pelo indivíduo social configurando, assim, a grande calamidade da banalização da injustiça social. 


\section{Considerações finais}

Diante das considerações dos autores elencados, neste ensaio de debates, sobre a subjetividade da complexidade humana - o sofrimento - e os mecanismos subjetivos de dominação do sistema vigente pelo trabalho, que geram também sofrimentos na sociedade, precisamos refletir criticamente a partir dessas diferentes vozes que tratam epistemologia, educação e sociedade de outros ângulos teóricos. São contribuições e estudos caros, pois suas pesquisas partem do lugar da vivência, da experiência e do testemunho de quem sofre; do lugar das vítimas na sociedade. Parece-nos que este seria o relevante debate que deveria ocupar a pauta das discussões sobre conhecimento e educação: qual é o verdadeiro impacto do sofrimento humano e social na produção do conhecimento e na significação da visão de mundo e sociedade (Das)? Quais os prejuízos na sociedade diante da banalização da injustiça social causada pelo sistema e assimilada alienadamente pelos trabalhadores (Dejours)? Vivemos uma vida humana ou uma perspectiva empresarial (Laval)? Se estes conceitos apontados estão de fato relacionados ao sofrimento social, como a Educação atuaria no processo de formação humana? O sofrimento não modificaria as faculdades do conhecimento?

$\mathrm{Na}$ perspectiva da educação integral humana, devemos conciliar as teorias educacionais tradicionais vigentes e cotejá-las às perspectivas educacionais que estejam fora do "centrismo epistemológico" para ouvirmos vozes da periferia, da heterodoxia, da vida humana. Esses autores são importantes vozes que chamam a atenção, convocandonos para um debate sobre novas formas de conhecer, pensar e educar com os diferentes, na luta pela não conformação, para a resistência e a revolução. Não se trata de apologia ao sofrimento, mas sim o seu contrário. O que discutimos aqui é como podemos fazer uma educação humana que compreenda a vida de quem queremos educar a partir do reconhecimento da vítima do sofrer como sujeito humano.

Por fim, sobre o trabalho na perspectiva da teodiceia, ainda podemos encontrar categorias estruturais que combatem as teologias-míticas conformadoras ao capital. Parece-nos relevante o comentário da perspectiva teológica de Paulo de Tarso como crítico desta lógica sobre o trabalho (por ex. Agambem ou Zizek), aquele que sempre valorizou a materialidade do corpo: "digno é o obreiro de seu salário" (I Tm 5.18). Esta é uma teodiceia para justiça - diké em grego. Ou seja, o trabalho deve ser reinscrito, pela sociedade e pela educação, para as dimensões da vida, da comunidade e das perspectivas de esperança, e não para o sofrimento e morte. $O$ trabalho deve ser resgatado para causar dignidade de justiça, de igualdade social e fraternidade humana para um mundo sempre melhor. 


\section{Referências}

ARENDT, H. Eichmann em Jerusalém: um relato sobre a banalidade do mal. Tradução José Rubens Siqueira. São Paulo: Companhia da Letras. 1999.

ARANTES, P. E. O Novo Tempo do Mundo. São Paulo: Editora Boitempo, 2014.

COELHO, A. da S. Capitalismo como religião: uma crítica a seus fundamentos míticoteológicos. Tese de doutorado. PPGCR - Universidade Metodista de São Paulo, São Bernardo do Campo - SP, 2014.

COELHO, A. da S. Legitimação teológica do sofrimento como pedagogia: crítica em Veena Das. Porto Alegre. Educação. Revista quadrimestral, 2017.

DARDOT, P.; LAVAL, C. A nova razão do mundo: ensaio sobre a sociedade neoliberal. São Paulo: Editora Boitempo. 2016.

DEJOURS, C. A banalização da injustiça social. Trad. Luiz Alberto Monjardim. Rio de Janeiro: Fundação Getúlio Vargas, 2001.

DUSSEL, E. 1492: O encobrimento do outro (A origem do "mito da modernidade"): Conferências de Frankfurt. Tradução Jaime A. Clasen - Petrópolis, RJ: Vozes, 1993.

GIACÓIA JR, O. Mal radical e mal banal. O que nos faz pensar. n. 29. Maio 2011, p. 137-169.

GIDDENS, A. As consequências da Modernidade. São Paulo: Editora UNESP, 1991.

GOLDMANN, L. Dialética e Cultura, Rio de Janeiro: Paz e Terra, 1979.

GRUSCHKA, A. Frieza burguesa e educação: a frieza como mal-estar moral da cultura burguesa na educação. Campinas, SP: Editores associados, 2014.

HINKELAMMERT, J. F. Crítica de la Razón Utopica. Bilbao: Ed. Desclée de Brouwer, 2002.

PUCCI, B.; ZAMORA, J. A.; MOREIRA, A. da S. Adorno, Educação e Religião. 1. ed. Goiânia: Editora da UCG - Univ. Católica de Goiás. 2008.

SUNG, J. M. Educar para Reencantar a Vida. Petrópolis: Vozes, 2006.

THOMPSON. Bíblia. Tradução João Ferreira de Almeida. Edição Contemporânea. São Paulo. Editora Vida. 1995.

ZAMORA, J. A. Hannah Arendt e T. W. Adorno: pensar contra a barbárie. Publicada na revista Arbor Ciência, Pensamento e Cultura. 2010 